\title{
Hydrolysis of Corn Oil Using Subcritical Water
}

\author{
Jair Sebastião S. Pinto and Fernando M. Lanças* \\ Instituto de Química de São Carlos, Universidade de São Paulo, CP 780, 13566-590 \\ São Carlos-SP, Brazil
}

\begin{abstract}
Este trabalho apresenta os resultados de um estudo sobre o uso da água subcrítica, como reagente e solvente, para a reação de hidrólise de óleo de milho sem o emprego de ácidos e base entre as temperaturas de $150-280^{\circ} \mathrm{C}$. A hidrólise de óleo de milho leva à formação dos seus respectivos ácidos graxos, com a mesma eficiência dos métodos convencionais. Os ácidos graxos formam um grupo importante de produtos, os quais são usados em diversas aplicações. A identificação e confirmação dos produtos da hidrólise foram feitos por HT-HRGC-FID e HRGC/MS.
\end{abstract}

This work presents the results of a study on the use of subcritical water as both solvent and reactant for the hydrolysis of corn oil without the use of acids or alkalis at temperatures of $150-280^{\circ} \mathrm{C}$. Corn oil hydrolysis leads to the formation of its respective fatty acids with the same efficiency of conventional methods. Fatty acids form an important group of products, which are used in a range of applications. The confirmation and identification of the hydrolysis products was done by HT-HRGC-FID and HRGC/MS.

Keywords: subcritical water, hydrolysis, fatty acids, corn oil

\section{Introduction}

The development of methodologies environmentally friend has been one of the principal objectives pursued by researchers of several areas as chemistry, process development and others. Ideally, the absence of organic solvents is a factor of major importance in any process, because they should be recycled, incinerated or submitted to an appropriate unitary operation that does not result in aggression to the environment.

Water in the sub or supercritical state presents unusual properties that have been raising a lot of interest as an alternative solvent. ${ }^{1-4}$ Many studies have been done exploring the use of water in conditions sub and supercritical to promote organic synthesis reactions, some of those would be alkyl-aromatics oxidation, oxidation of methane in hydrothermal systems, dehydration of alcohol, and organic transformations catalyzed by metals. ${ }^{1}$

Another option is the employment of subcritical water as both solvent and reagent for triglycerides hydrolysis. ${ }^{5}$ Some studies utilizing pressures higher than $2 \mathrm{MPa}$ and temperature over $250{ }^{\circ} \mathrm{C}$, demonstrate the viability of its use without the need of using either acidic or alkaline catalysts.

* e-mail: flancas@iqsc.usp.br
Hydrolysis of oils is the applied term to the operation in which water reacts with oil to form glycerol and fatty acids. ${ }^{6}$ This process is commercially important because the fatty acids are used for soap production, synthetic detergents, greases, cosmetics, and several other products. ${ }^{7-9}$

The soap production starting from triglycerides and alkalis is accomplished for more than 2000 years by the Man. ${ }^{10}$



where $\mathrm{C}_{3} \mathrm{H}_{5}(\mathrm{OCOR})_{3}$ represents triglycerides, $\mathrm{RCOOH}$ represents any fatty acid and $\mathrm{C}_{3} \mathrm{H}_{5}(\mathrm{OH})_{3}$, glycerol.

Several authors propose that this reaction is processed in stages, starting from the triglycerides for diglycerides, monoglycerides and glycerol, and to each stage there is liberation of a fatty acid. This reaction is homogeneous of first order in the oily phase. ${ }^{10}$

As water and the oil are insoluble at low temperature, the reaction in these conditions is extremely slow. Increasing the temperature the oil solubility in water increases and the speed of the reaction accelerates quickly. An increase of $10{ }^{\circ} \mathrm{C}$ in the temperature increases the rate of reaction of a factor ${ }^{10}$ from 1.2 to 1.5 . 
Sturzenegger and Sturm ${ }^{11}$ demonstrated that the hydrolyses degree is not a function of the temperature to obtain equal yield approximately in equilibrium the temperature of 225,240 and $280^{\circ} \mathrm{C}$; the reaction velocities varied with the temperature. ${ }^{10}$

The water-oil ratio is the limit factor for this reaction. The yield in equilibrium is independent of the temperature or catalyst and it is determined for the water-oil ratio. The reason is due to the fact that the displacement of the reaction happens in the direction of the reagents with the increase of the glycerol concentration; then it is of fundamental importance to control the percentage of water. ${ }^{12}$

\section{Materials and Methods}

Distilled water was deionized in a Milli Q Millipore (Bedford, MA, USA) system. Hexane degree PA was supplied by Merck (Rio de Janeiro, RJ, Brazil); Methanol degree HPLC by Mallinckrodt Baker Inc (Paris, Kentucky, USA); mixture 61C of fatty acid methyl esters supplied by PolyScience (Niles, IL, USA). The hydrolyses reaction vessel was built of stainless steel $(7.5 \mathrm{~cm}$ x $0.4 \mathrm{~cm}$ i.d.), and used in a GC oven from CG Instrumentos Científicos (São Paulo, SP, Brazil).

\section{Samples}

The corn oil sample (Milleto) used was bought in the local trade, and it did not suffer any treatment before the hydrolysis.

\section{Hydrolysis}

Triplicate $150 \mathrm{mg}$ corn oil and $1000 \mathrm{mg}$ of deionized water previously degassed with helium, in the proportion of 85:15 approximately were used. The mixture was placed into the hydrolysis vessel, which was closed in the extremities, and placed in the CG oven previously equilibrated to the desired temperature, for $40 \mathrm{~min}$.

The temperature variation (150, 200, 225, 250 and 280 ${ }^{\circ} \mathrm{C}$ ) had the purpose of studying the hydrolysis yield as a function of the temperature, maintaining the constant time.

After having accomplished the hydrolysis, the resulting mixture of two phases was separated. The oil phase was analyzed by high temperature gas chromatography with flame ionization detector (HT-HRGC-FID) and in a gas chromatograph coupled with mass spectrometry (HRGC/ MS). In these conditions was determined the concentration, based on the area of the chromatograph peak, of the triglycerides, fatty acids and monoglycerides in the reactional system.

\section{Triglycerides analysis by HT-HRGC}

The resulting oil was diluted to $2 \mathrm{~mL}$ with hexane PA, and injected into a HP 5890 Series II GC gas chromatograph fitted with a split/splitless injector. The injection port temperature was $360{ }^{\circ} \mathrm{C}$. The chromatographic separation was made with a CROMA-5 HT (9 m x 0.25mm i.d. x 0.09 $\mu \mathrm{m})$ column. The oven program was as follows: $150{ }^{\circ} \mathrm{C}$ for $1 \mathrm{~min}$, to $380{ }^{\circ} \mathrm{C}$ at $8^{\circ} \mathrm{C} \mathrm{min}^{-1}$, held for $10 \mathrm{~min}$. The column flow was of $3.5 \mathrm{~mL} \mathrm{~min}^{-1}$, with hydrogen as carrier gas; split ratio was 1:10.

The identification of the triglycerides was made by comparing the retention times of the components of interest with the retention time of the triolein (T54) analytical standard, as well as by comparison with data from literature. ${ }^{13}$

\section{Fatty acids analysis by HRGC/MS}

The identification of the fatty acids was accomplished by gas chromatography coupled with the mass spectrometer using a Shimadzu model GCMS-QP 5000 GC/MS fitted with a split/splitless injector. The injection port temperature was set to $260{ }^{\circ} \mathrm{C}$. Spectra between $\mathrm{m} / \mathrm{z}, 40$ and 475 were recorded for each compound. Identification was made by comparing with the retention times of the standard mixtures and the mass spectra in SCAN mode. The mass spectrometer was operated in SCAN mode, and ionization was carried out in the electron impact (EI, ionization energy, $70 \mathrm{eV}$ ) mode. The transfer line temperature was maintained at $280{ }^{\circ} \mathrm{C}$. The chromatographic separation was made with a CROMA-5 [Poly(5\% phenyl 95\% methylsiloxane)] (30m x $0.25 \mathrm{~mm}$ i.d. $\mathrm{x} 0.3 \mathrm{~mm}$ ) column with the following heating ramp: $100{ }^{\circ} \mathrm{C}$ for $2 \mathrm{~min}$, to $225^{\circ} \mathrm{C}$ at $10^{\circ} \mathrm{C} \mathrm{min}^{-1}$, held for $10 \mathrm{~min}$, to $310^{\circ} \mathrm{C}$ at $4{ }^{\circ} \mathrm{C} \mathrm{min}^{-1}$, and held for $10 \mathrm{~min}$. The split ratio was $1: 10$, the linear velocity of $39.3 \mathrm{~cm} \mathrm{~s}^{-1}$; the carrier gas was ultra pure helium, with the injection port temperature at $250{ }^{\circ} \mathrm{C}$.

\section{FAME analysis by HRGC/MS}

To verify the possibility of alterations, or decompositions of the fatty acids due to the high temperature employed during the analysis, the FAME (fatty acids methyl ester) analysis of the original oil before any process was accomplished being the results compared with those of the fatty acids. For that purpose $35 \mathrm{mg}$ of corn oil sample was weight into $20 \mathrm{~mL}$ tube with screw cap and 0.5 $\mathrm{mL}$ methanolic solution $0.5 \mathrm{~mol} \mathrm{~L}^{-1}$ sodium hydroxide was added and the contents of the capped tube are heated in a water bath (temperature $90{ }^{\circ} \mathrm{C}$ ).

After $10 \mathrm{~min}$ the tube is removed from the bath, and cooled in an ice bath. Then $1.5 \mathrm{~mL}$ of esterification solution 
(ammonium chlorite, methanol, sulfuric acid) are added and the contents of the capped tube heated in water bath (temperature $90{ }^{\circ} \mathrm{C}$ ) for $10 \mathrm{~min}$, being after words cooled in ice bath and later added $5 \mathrm{~mL}$ of hexane and $10 \mathrm{~mL}$ of water. A sample is taken from the clear upper layer (usually $1 \mu \mathrm{L}$ ) for $\mathrm{GC}$ analysis of FAMEs.

The identification of the methyl esters was accomplished using gas chromatography coupled with a mass spectrometer Shimadzu model GCMS-QP 5000 fitted with injector split/ splitless. The injection port temperature was $260{ }^{\circ} \mathrm{C}$. The chromatographic separation was made with a column CHROMA-5 (30m $\times 0.25 \mathrm{~mm}$ i.d. $\times 0.3 \mathrm{~mm}$ ) with the following heating ramp: $150^{\circ} \mathrm{C}$ for $5 \mathrm{~min}$, to $180^{\circ} \mathrm{C}$ at $5{ }^{\circ} \mathrm{C}$ $\mathrm{min}^{-1}$, held for $10 \mathrm{~min}$, to $300{ }^{\circ} \mathrm{C}$ at $8{ }^{\circ} \mathrm{C} \mathrm{min}^{-1}$. The split ratio was $1: 10$, the linear velocity of $38 \mathrm{~cm} \mathrm{~s}^{-1}$, the carrier gas was helium ultra pure. The identifications were made comparing with the retention times of the standard mixtures and the mass spectra in the SCAN mode. The mass spectrometer was operated in SIM mode, and ionization was carried in the electron impact mode $(70 \mathrm{eV})$. The transfer line temperature was maintained at $280^{\circ} \mathrm{C}$.

\section{Results and Discussions}

\section{Hydrolysis of the corn oil}

The study of the variation of the yield of the hydrolysis as a function of the temperature evidenced similar results to the reported in the literature. ${ }^{1,5}$ It was verified that to low temperatures, the speed and the yield of the hydrolysis reaction are both practically null. Figure 1 and Table 1 illustrates a typical profile of triglycerides (TG) obtained of non hydrolyzed corn oil, while Figures 2 to 3 illustrate

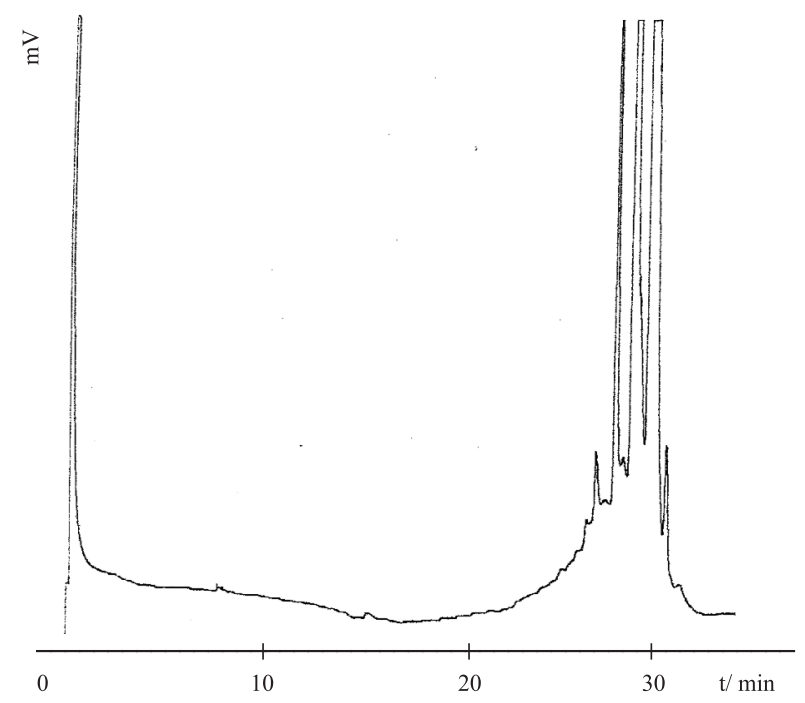

Figure 1. HT-HRGC-FID chromatogram of a typical profile of corn oil triglycerides by HT-HRGC-FID. TG= triglycerides.
Table 1. Composition of triglycerides of the corn oil

\begin{tabular}{cccc}
\hline Triglycerides & mean & SD & \%RSD \\
\hline T54 & 59.97 & 1.38 & 2.30 \\
T52 & 32.22 & 1.28 & 3.97 \\
T50 & 4.61 & 0.59 & 12.80 \\
T48 & 0.97 & 0.15 & 15.38 \\
\hline
\end{tabular}

the variation of the chromatographic profile of a hydrolyzed corn oil as a function of the temperature. With the increase of the temperature (Figures 2,3) an increase in the concentration of the fatty acids and decreases of the concentration of the triglycerides is observed, fact this that supports the hydrolysis model under investigation.

Figure 4, displays a general view of the behavior of the hydrolysis yield as a function of the temperature. With an increase of $30^{\circ} \mathrm{C}$ in the hydrolysis temperature the reaction rate was multiplied by a factor of 1.25 .



Figure 2. HT-HRGC-FID chromatogram of a corn oil hydrolyzed at $250{ }^{\circ} \mathrm{C}$. FA-fatty acid; MG- monoglycerides; T54-triglycerides with 54 carbons.

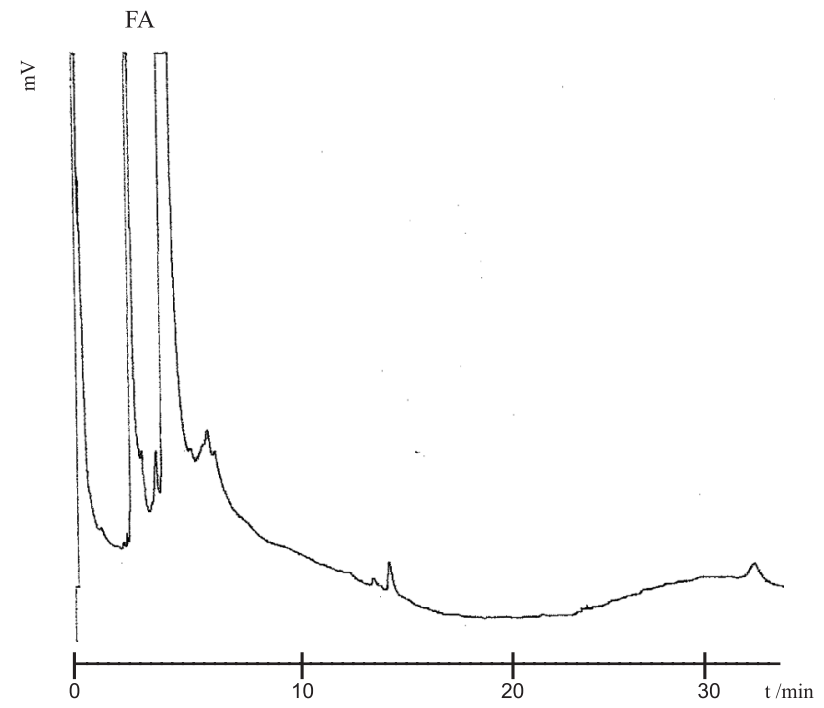

Figure 3. HT-HRGC-FID chromatogram of a corn oil hydrolyzed at $280{ }^{\circ} \mathrm{C}$. 


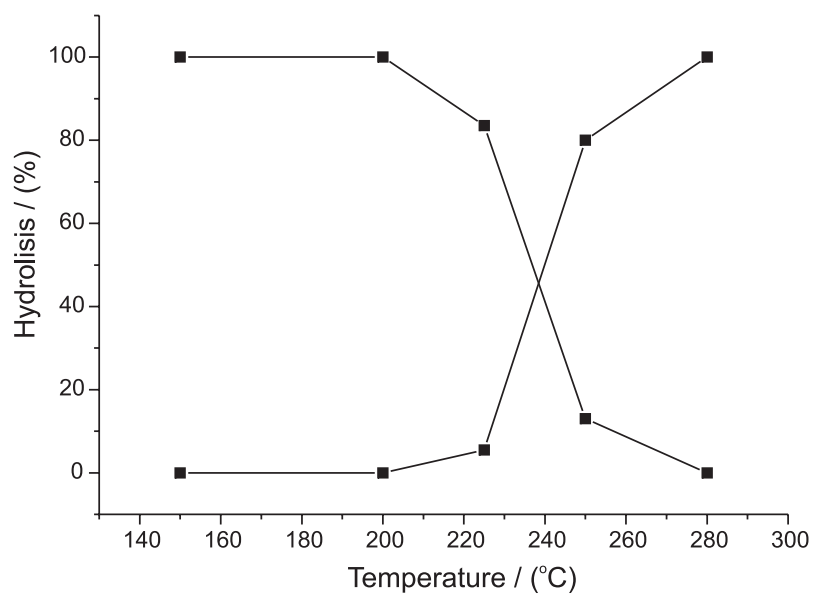

Figure 4. Graphic representation of corn oil hydrolysis as a function of temperature.

\section{HRGC/MS and FAME analysis}

Table 2 shows a comparison of the composition of the fatty acids as determined directly by HRGC/MS, through FAMEs analysis, also using HRGC/MS and data from the literature.

The analyses made by mass spectrometry had as goal the positive identifications of acids fatty, intermediate products formed in the hydrolysis, as well as the methyl esters by FAMEs (Figures 5, 6).

Table 2. Composition of fatty acids of the corn oil

\begin{tabular}{lccc}
\hline Fatty Acids & $\begin{array}{c}\text { HRGC/MS } \\
(\%)\end{array}$ & $\begin{array}{c}\text { FAME-HRGC/MS } \\
(\%)\end{array}$ & $\begin{array}{c}\text { Literature }^{13,14} \\
(\%)\end{array}$ \\
\hline Palmitic & 13.91 & 14.84 & $12-15$ \\
Stearic & 6.50 & 2.90 & $2-3$ \\
Oleic & 29.50 & 35.49 & $28-40$ \\
Linoleic & 45.03 & 44.53 & $45-55$ \\
Linolenic & $\mathrm{a}$ & $\mathrm{a}$ & $05-0.9$ \\
Araquidic & $\mathrm{nd}$ & 0.61 & 0.5 \\
Gadoleic & $\mathrm{nd}$ & 0.32 & 0.4 \\
\hline
\end{tabular}

a: The column CROMA-5 does not separate the linoleic and linolenic fatty acids. The result is the addition of them; nd: not detected.

The obtained data are within the variation suggested by the literature, ${ }^{13,14}$ because the composition depends on the variety of the corn, soil, climate and agricultural treatments.

Except for the Araquidic and Gadoleic acids, not found after the hydrolysis in our samples, the comparative data indicate that the hydrolysis does not cause the decomposition of the fatty acids. The absence of the mentioned acids perhaps is due to the fact that they are in very low concentration and in this experiment conditions they are not detected.

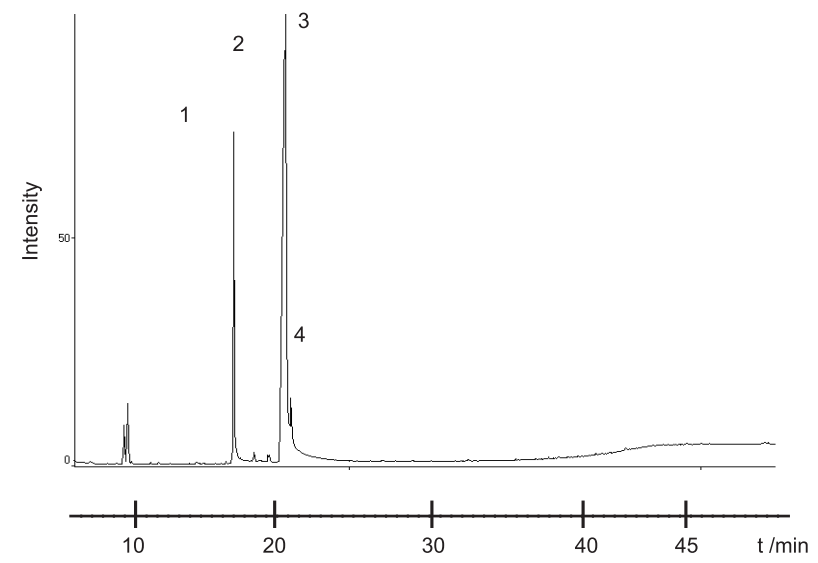

Figure 5. Total ion chromatogram (TIC) of a corn oil sample hydrolyzed at $280{ }^{\circ}$ C. 1. Palmitic acid; 2. Linoleic and Linolenic acid; 3. Oleic acid; 4. Stearic acid.

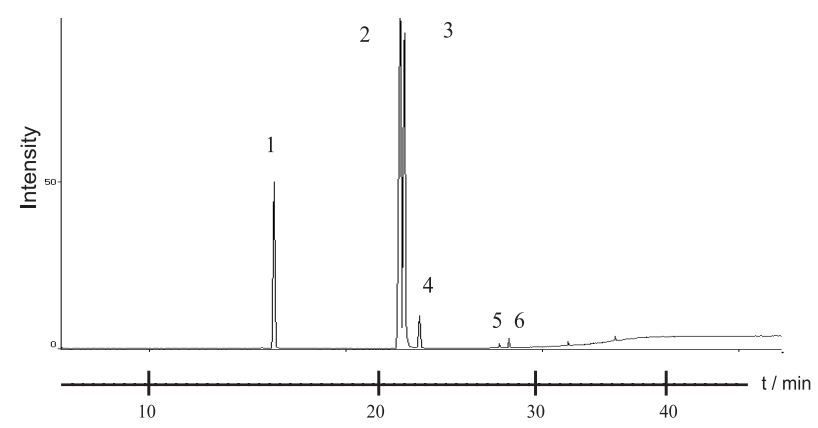

Figure 6. Total ion chromatogram (TIC) of corn oil FAME. Methyl esters 1. Palmitic acid; 2. Linoleic and Linolenic acid; 3. Oleic acid; 4. Stearic acid; 5. Gadoleic acid; 6. Araquidic acid.

\section{Conclusions}

Corn oil hydrolysis, under subcritical water, leads to the formation of its respective carboxylic acids with the same efficiency of conventional methods. Hydrolysis occurs rapidly at $280{ }^{\circ} \mathrm{C}$, yielding $100 \%$ of the conversion. The triglycerides analysis could be done by HT-HRGCFID, without degradation.

\section{Acknowledgments}

The authors thank the CAPES, CNPq and FAPESP for financial support.

\section{References}

1. Holliday, R.L.; King, J.W.; List, G.R.; Ind. Eng. Chem. Res. 1997, 36, 932.

2. Khuwijitjaru, P.; Fujii, T.; Adachi, S.; Kimura, Y.; Matsuno, R.; Chem. Eng. J. 2004, 99, 1.

3. Oomori, T.; Khajavi, S.H.; Kimura, Y.; Adachi, S.; Matsuno, R.; Biochem. Eng. J. 2004, 18, 143. 
4. Moreschi, S.R.M.; Petenate, A.J.; Meireles, M.A.A.; J. Agric. Food Chem. 2004, 52, 1753.

5. King, J.W.; Holliday, R.L.; List, G.R.; Green Chem. 1999, Dec, 261.

6. Lawson, H.W.; Standards for Fats \& Oils, AVI Publishing Company, Inc.: Westport, Connecticut, 1985.

7. Reinish, M.D.; J. Am. Oil Chem. Soc. 1956, 33, 516.

8. Pryde, E.H.; Fatty Acids, $2^{\text {nd }}$ ed., The American Oil Chemist's Society-Champaign: Illinois, 1985.

9. Swern, D.; Bailey's Industrial Oil and Fat Products, John Wiley \& Sons: New York, 1979, vol. 2.
10. Ackelsberg, O. J.; J. Am. Oil Chem. Soc. 1958, 35, 635.

11. Sturzenegger, A.; Sturm, H.; Ind. Eng. Chem. 1951, 43, 510.

12. Lawrence, E.A.; J. Am. Oil Chem. Soc. 1954, 31, 542.

13. O'Brien, R.D.; Fats and Oils-Formulating and Processing for Applications, Technomic Publishing Co. Inc.: Lancaster, PA, 1998.

14. Antoniosi Filho, N.R.; PhD. Thesis, Instituto de Química de São Carlos, Universidade de São Paulo, São Carlos, 1995.

Received: April 18, 2005

Published on the web: December 1, 2005

FAPESP helped in meeting the publication costs of this article. 